\title{
Data-Driven Modelling of Daylight Scattering by Roman Window Glass
}

\author{
Lars O. Grobe ${ }^{1}$, Andreas Noback ${ }^{2}$, and Franziska Lang ${ }^{2}$ \\ ${ }^{1}$ Lucerne University of Applied Sciences and Arts \\ ${ }^{2}$ Technische Universit at Darmstadt
}

\begin{abstract}
With the advent of window glass, its optical properties arise as one important factor in the illumination, and thereby the visual perception, of Roman architecture. Computational simulation allows to reconstruct the daylight illumination of buildings with known geometrical configuration, if the scattering properties of window glass can be replicated. We describe a method to generate data-driven models of Roman window glass based on precise gonio-photometric measurements of archaeological finds. The method is employed to model four exemplary glass finds in the context of a simplified architectural scene, demonstrating the potential to support research in building history and archaeology focused on building techniques, lighting concepts and perception with accurate and reliable photometric data.
\end{abstract}

Keywords: Roman window glass, Roman architecture, daylight, light scattering, daylight simulation

\section{Introduction}

In archaeology, the material attributes of Roman window glass can be discussed within two contexts: First as physical remains of antique technology and therefore evidence in the research on the origins of raw materials, (centralised) raw glass production, trade, recycling and the (probably local) manufacture of panes or domes. Secondly as physical properties affecting the application of window glass in ancient architecture and therefore an element in its research. Combining both aspects, the material attributes can act as a link between these contexts, and guide research on the relation between glass production and application as well as its interdependent development over time.

Besides the geometry, thickness, size and form, physical and chemical durability of Roman window glass, its optical properties - specifically spectral transmittance and scattering - affect its usage. These properties are the measurable effects of chemical and geometric features (Figure 1). In the spatial context of an architectural interior, they affect illumination in relation to the optical properties of reflective surfaces and the characteristics of incident light. The illumination of an ancient interior can be studied by means of lighting simulation applied to a spatial reconstruction of its architecture. For such Cultural Heritage Predictive RenderingHappa et al. (2012, 2010), the acquisition and modelling of the optical properties of Roman window glass is a necessity and not well researched Earl et al. (2013).

This article aims to meet this demand with regard to light scattering by flat Roman window glass, and to exemplify how glass properties as results of manufacturing processes relate the illumination of an architectural interior.

\section{State of Research}

\subsection{Production and proliferation of Roman window glass}

The invention of window glass is an important keystone in the development of architecture. Window glass is first applied in Roman baths in the first century BC Baatz (1991) (Komp, 2009, p. 24). Finds of window glass of similar time-frames from different sites in the Roman empire resemble each other in regard to colour, thickness, surface structure and chemical composition Bachmann (2011); Gliozzo et al. (2013); Komp (2009); Arletti et al. (2010). Window glass was produced independent of location in a similar fashion Drauschke and Greiff (2008); O'Hea (2001). Raw glass originated from centralised production (Komp, 2009, p. 205), with a focus along the eastern Mediterranean coast Saguì (2008); Freestone et al. (2008). This centralised production ended in the second half of the first millennium. A rise in the use of plant ash in glass from Great Britain since the 6th century has been diagnosed, indicating a more localised production Freestone et al. (2008). Similar findings for early Byzantine glass from Caričin Grad Drauschke and Greiff (2008), and a disruption of raw glass production at the eastern Mediterranean coast in the 9th century after natron from Egypt has become unavailable have been reported Saguì (2008).

There is no evidence indicating a similar centralisation of further processing steps in glass production. It has to be assumed that raw glass from various production sites was rather processed in small local workshops, or by itinerant craftsmen (Komp, 2009, pp. 206,211,216). Nevertheless, there is some evidence of trade with finished products Komp (2009). Roman window panes were mostly produced in rectangular shape with typical sizes of $20 \mathrm{~cm}$ to $80 \mathrm{~cm}(\mathrm{Komp}$, 2009, p. 20). Other types such as circular domed panes in occuli Fontaine and Foy (2008), and crown glass Fontaine and Foy (2008); Allen (2002) are documented. 


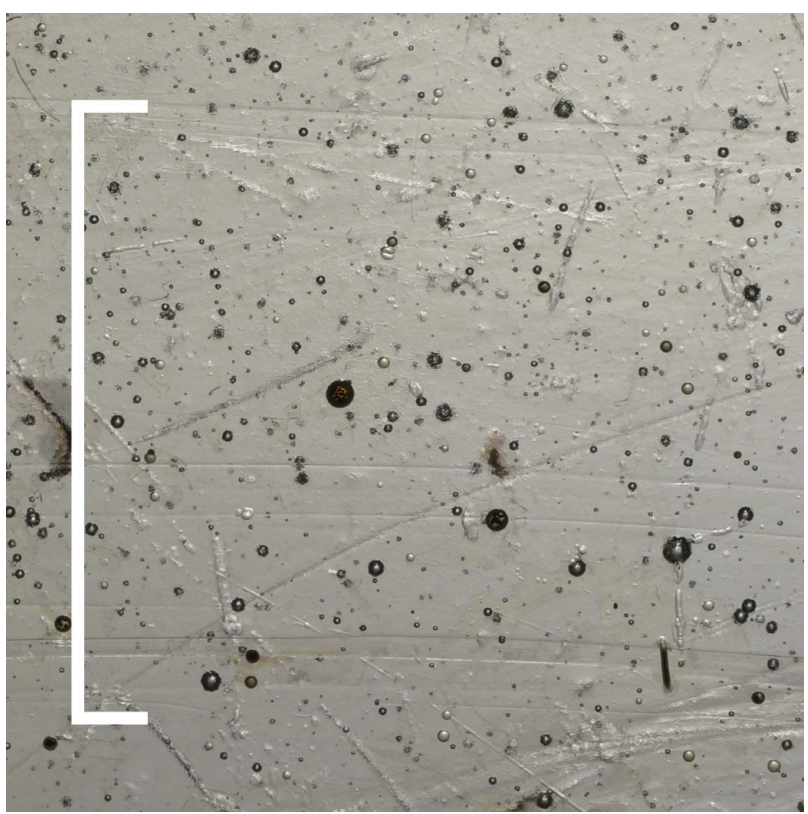

(a)

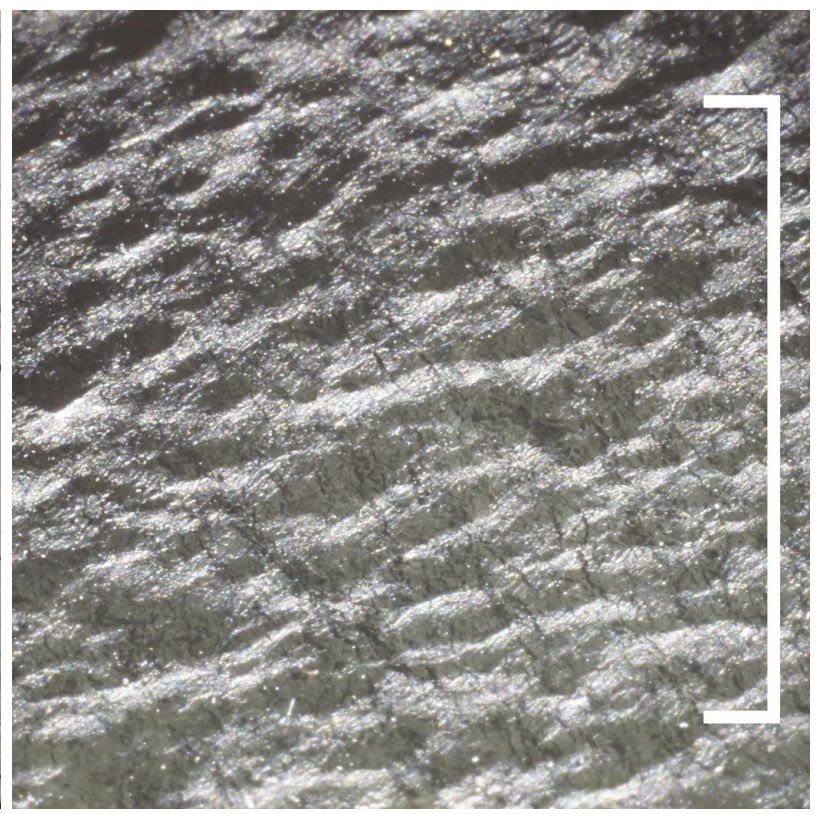

(b)

Figure 1: (a) Air inclusions and surface imperfections on a sample of blown window glass (sample G3) Noback et al. (2018). (b) Leather-like surface structure of a sample of the matte-glossy type (G1). The features are typical for Roman window glass and cause scattering of transmitted and reflected light $(l=10 \mathrm{~mm})$.

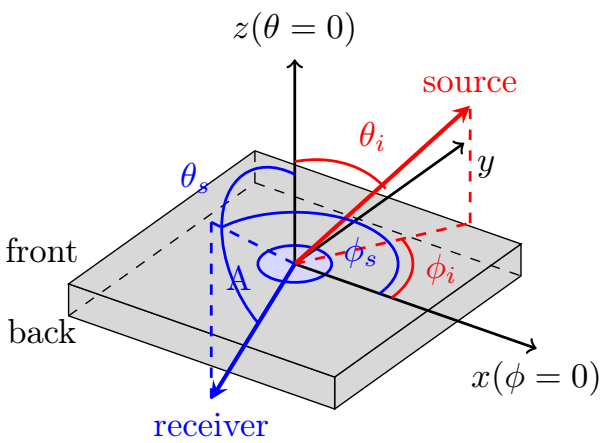

Figure 2: Coordinate system and notation of directions to source $\left(\theta_{i}, \phi_{i}\right)$ and receiver $\left(\theta_{s}, \phi_{s}\right)$ relative to the sample in the measurement of the BSDF as averaged over the sampling aperture $A$ Noback et al. (2018).

\subsection{Measurement of light scattering}

Light scattering is described by the Bidirectional Scattering Distribution Function (BSDF) as a function of the incident direction to the light source (subscript i), and the outgoing, or scattering direction toward which light is leaving the sample (subscript s) ASTM E2387-05 (2011); Nicodemus et al. (1977). Both directions are typically notated as spherical coordinates $\left(\theta_{i}, \phi_{i}\right)$ and $\left(\theta_{s}, \phi_{s}\right)$ relative to the sample (Figure 2). The BSDF is implicitly defined for an infinitely small surface area by the rendering equation Kajiya (1986):

$$
L_{s}\left(\theta_{s}, \phi_{s}\right)=\int_{\theta_{i}, \phi_{i}}^{\omega_{i}=4 \pi} \operatorname{BSDF}\left(\theta_{i}, \phi_{i} ; \theta_{s}, \phi_{s}\right) \cdot L_{i}\left(\theta_{i}, \phi_{i}\right) \cdot \cos \left(\theta_{i}\right) \cdot d \omega_{i}
$$

with $L_{s}$ being the scattered, $L_{i}$ the incident radiance and $\omega_{i}$ the solid angle subtended by the light source.

Measurements of the BSDF inevitably imply several limitations Apian-Bennewitz (1995):

- The continuous BSDF can be sampled only by a finite number of directions.

- The BSDF is averaged over the solid angles of light source and detector.

- The BSDF is averaged over the observed surface area of the sample, the sampling aperture $A$, which has to be large enough to cover a representative region. 
The effects of such sampling and averaging define, together with electric noise and scattering by the illuminating optics, a characteristic instrument signature, that determines the lowest measurable BSDF and limits the achievable directional resolution Stover (2012).

The BSDF is measured by relating the light reaching a detector from a sample under known illumination for combinations of incident and outgoing directions Apian-Bennewitz (2010). Instrumentation is implemented either by scanning or imaging techniques Krehel et al. (2015). Scanning gonio-photometers acquire the BSDF for varying incident and outgoing directions by mechanical movement. The sequential recording of the BSDF allows to adjust e.g. amplification to the signal, accommodating a high dynamic range, and to refine the directional resolution of measurement Apian-Bennewitz and Hardt (1998). Imaging gonio-photometers aim to decrease the time required for the BSDF measurement by the simultaneous acquisition for many scattered directions. This is implemented by assigning the pixels of the imaging sensor to the corresponding scattered directions by reflective or refractive optics. Dynamic range and resolution of imaging gonio-photometers are typically lower than those of scanning instruments Meyen et al. (2014).

\subsection{Scattering models for daylight simulation}

Lighting simulation requires models that evaluate to reflection and transmission for arbitrary pairs of incident and scattered directions. These representations of the BSDF can broadly be categorised into parametric descriptions of light scattering, either phenomenological or analytical, and data-driven models Kurt and Edwards (2009). Phenomenological models are more widespread in daylight simulation and aim to replicate an observation with few, easily measurable variables or by fitting to measured BSDFs Ngan et al. (2005). Often the BSDF is represented as a combination of lobes, modelling directional scattering, and a diffuse background Geisler-Moroder and Dür (2010). Analytical models are parametrised by properties that relate light scattering to explanatory concepts from physics (e.g. micro-facet theory Walter et al. (2007)). Thereby analytical models allow to contrariwise reveal such properties by fitting a theoretical model to measured BSDFs.

While analytical and phenomenological models cover a broad spectrum of scattering phenomena, they lack generality. A fundamentally different approach is the direct utilisation of measured data by data-driven models Matusik et al. (2003). Due to the discrete nature of BSDF measurements, such models imply interpolation, typically by an intermediate set of basis functions, and extrapolation. Efficient techniques for data-reduction, storage and look-up are essential to handle the large volumes of discrete data when high directional resolution is to be achieved.

RADIANCE is a thoroughly validated, open-source daylight simulation suite that implements physically plausible, parametric reflection and transmission models, as well as a compact data-driven model. The model achieves high, locally adaptive directional resolution (up to $1.5^{\circ}$ for anisotropic cases) and was developed to replicate the transmission properties of optically complex fenestration. Even highly irregular, computed or measured BSDF can be compiled into the data-driven model by a tool-chain distributed with the software Ward et al. (2012, 2014); Grobe et al. (2017). The software by default employs backward ray-tracing, a rendering technique that achieves photo-realistic and physically valid imagery but cannot model effects such as irregular deflection and concentration of light by reflection and refraction (Ward and Shakespeare, 1998, f. 579f.)Kider et al. (2009). This shortcoming is addressed by bidirectional photon mapping, that optionally replaces the backward algorithm in the diffuse inter-reflection calculation and allows accurate replication e.g. of caustics Jensen (2001); Schregle (2004). Besides its application to geometric models of reflectors and fenestration systems, photon mapping has been demonstrated to accelerate image synthesis with data-driven models under directional illumination Grobe (ress).

\subsection{Transparency and translucency in case studies that reconstruct illumination}

The effect of light scattering, not by glass but by thin marble tiles covering the Demeter temple at Sangri on the island of Naxos (Greece), has been modeled to synthesise images for an assessment of the roof's appearance and its effect on the illumination of the interior. The model is based on transmission measurements under diffuse illumination, and does not account for directional dependency or non-diffuse transmission Ohnesorg (2011). The generated imagery has been reused to visually match renderings of the temple of Zeus in Olympia (Greece), which is assumed to be illuminated through a similar, translucent roof, since the transmission properties as required for a simulation are unknown. The generated visualisations have been employed in an evaluation of different hypotheses about the illumination of the colossal statue of Pheidias located in the temple Patay-Horváth (2016).

Dielectric solids, that are constraint by non-planar interfaces, form a particular case of transmission that is characterised by deflection and potentially concentration of light. The effect, referred to as caustics, has been studied for the case of the oil lamps of the Mosque of Cordoba in a simulation study Kider et al. (2009). The caustics caused by the partially filled glass vessels were acquired by cameras and translated into a data-driven description, that appears to be similar to ray files as measured in near-field gonio-photometry of modern luminaires IES TM-25 (2013).

A model of light transmission through medieval stained glass has been developed based on ellipsiometric measurements on samples of different kinds of glass comprising the windows Cerise et al. (2012). To acquire the scattering 
properties of an entire window in the the cathedral of Lausanne (Switzerland) in situ, the spatially varying transmission properties of the stained glass were reconstructed by combining images under varying, natural illumination with a dictionary of laboratory measurements on comparable samples. The model allows relighting - the generation of images of the cathedral's rose window under arbitrary sky conditions - by multiplication of a matrix representation of the BSDFs with an illumination vector Thanikachalam et al. (2016).

The effects of window techniques, coloured and translucent glazing, scattering by translucent divisions and the illumination through adjacent spaces have been studied in detail for the case of the Katholikon in the Monastery of Hosios Loukas (Greece). The light simulation software LiGHTSCAPE was employed to reconstruct the illumination, and to assess the interplay of light, interior surfaces, and building geometry. Details of the modelling of window panes or other transmissive and reflective building elements are not given Piotrowski (2006).

The data-driven model as implemented in RADIANCE has been employed to model light scattering by window panes in a detailed simulation model of 6th century Hagia Sophia in Istanbul (Turkey). The effects of different glass types on horizontal illuminance distribution, shadow patterns and the three-dimensional perception of shapes and reliefs were demonstrated Noback et al. (2018).

\subsection{Objectives}

To enable the simulation-based reconstruction of the illumination and its influence on the perception of the interior of Roman architecture,

1. the BSDF of four finds of Roman window glass have been measured for the first time,

2. these measurements have been compiled into data-driven transmission models,

3. the models have been employed in daylight simulations for a simplified room model, and

4. the effects of light scattering properties on the illumination of that room have been evaluated based on the synthesised images.

The authors aim to provide a general, reliable and accurate method to base research on the interplay of glass-making and the perception of interiors under natural illumination employing reconstruction and computational simulation on quantitative, photometric grounds.

\section{Four samples of Roman window glass}

\subsection{Selection of exemplary samples by manufacturing techniques}

Four glass fragments (G1-G4) were selected from the archaeological collection of the LVR-LandesMuseum (Bonn, Germany). The set of exemplary samples, shown in Figure 3, is not representative for Roman glass in general, but rather chosen to cover a wide spectrum of provincial Roman window glass finds in terms of distinct and typical surface features, based on knowledge regarding production methods for rectangular Roman window panes:

1. Formed window glass comprises one matt and one glossy surface. It is translucent rather than transparent and typically between 3 and $6 \mathrm{~mm}$ thick. It was produced by pouring molten glass on a planar surface. With various tools, the mass was flatten and stretched into a rectangular pane Wiesenberg (2016). During this process the glass cools down fast, probably causing the frequently found, leather like structure. Formed glass often comprises remains of sand that has been used as abherent (Komp, 2009, pp. 60ff.). The sides and corners are typically thicker than the centre and showing tool marks. This glass has been common in the early Roman empire Arletti et al. (2010).

2. Blown window glass is thinner and comprises two glossy surfaces. It can be described as genuinely transparent but shows more distortion and stray light than today's window glass. In its production, a cylinder was blown, cut and flattened Wiesenberg (2016). It can be wavy and often shows a lot of air bubbles (Komp, 2009, pp. 73ff.). This glass emerged in the end of the 2nd century (Komp, 2009, p. 69) and dominates the finds since then Arletti et al. (2010).

The inclusion of the samples into the museum's collection dates back several decades. Unfortunately, initial cleaning and preparation of the samples was not documented. Find context and dating are reported in Table 1 Komp (2009).

\subsection{Results of visual inspection, macro photography and microscopy}

The four samples were visually inspected to record the optical relevant features of their surfaces and glass mass, and to search for evidence of production methods, contaminants, results of corrosion and cleaning marks. This was complemented by macro photography and microscopy (Figure 4). 

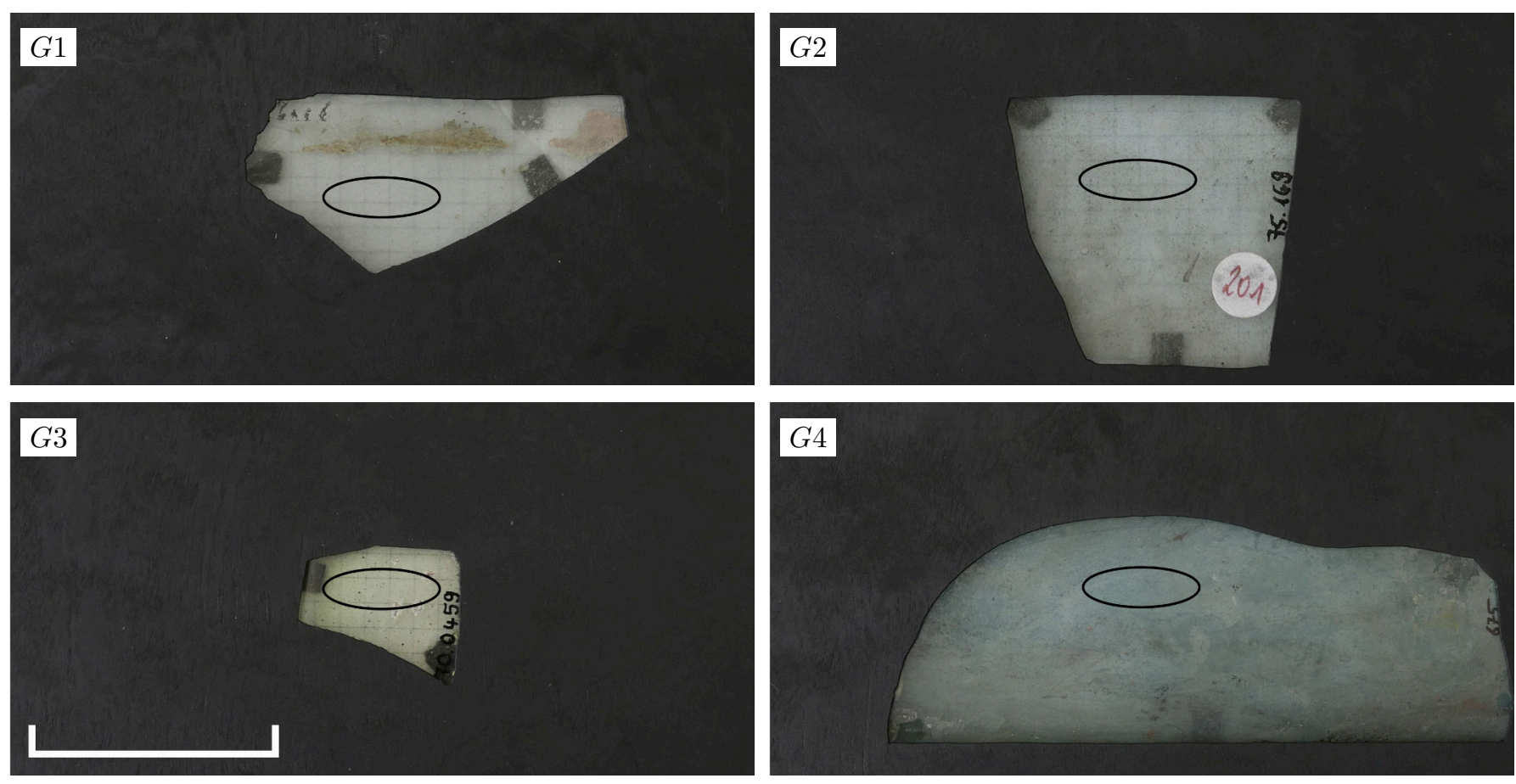

Figure 3: Samples G1-G4 in their mounts. The ellipses illustrate the effective sampling apertures for $\theta_{i}=60^{\circ}, \phi_{i}=0^{\circ}$ $(l=50 \mathrm{~mm})$.

G1: formed window glass with leather-like structure. Smooth side: irregular distributed signs of slight corrosion with small holes; some areas of more evolved corrosion. Matt side: elongated wavy structure $(\lambda \approx 1 \mathrm{~mm})$ with round and lenticular dimples (Figure 1(b)); some deeper round dimples; remains of mortar; slight scratches diagonal to surface structure, probably from cleaning; slight signs of corrosion. Glass mass: few, small $(\varnothing<0.3 \mathrm{~mm})$ perfectly round bubbles. Edges: sharp. Thickness: $2.1 \mathrm{~mm}$ to $4.7 \mathrm{~mm}$.

G2: formed window glass with flat lower side. Smooth side: scratches of irregular orientation with deposit, few longitudinal dimples, few signs of corrosion. Matt side: flat with little unevenness $(\lambda \approx 10 \mathrm{~mm})$; regular distributed small dimples (imprint of abherent?), showing irregular sharp edges under the microscope, filled with deposit; few signs of corrosion. Glass mass: Compared to $G 1$ more small round bubbles. Edges: sharp, one edge uniformly rounded. Thickness: $3.7 \mathrm{~mm}$ to $5.2 \mathrm{~mm}$.

G3: blown window glass. Two smooth sides: stronger iridescent corrosion with longitudinal corrosive structure (Figure 4(b)), brownish areas with inclusions and more evolved corrosion; surface partly chipped; curved ridges (Figure 4(a)). Glass mass: plenty round bubbles. Edges: sharp, one edge uniformly melted. Thickness: $1.9 \mathrm{~mm}$ to $2.9 \mathrm{~mm}$. The rounded edge and the curved ridges indicate that this piece may just as well be a flat part of a vessel.

G4: formed window glass with signs of grinding. Smooth side: uneven, distinctly thicker towards the edge, slight signs of iridescent corrosion, probably partly removed. Matt side: deep parallel scratches, dimples as leftovers from air bubbles opened by grinding or imprints from sand; some grains of sand flush with the surface (Figure 4(c)); beginning corrosion filled with deposit. Glass mass: plenty round bubbles. Edges: sharp, one edge perfectly straight and uniformly rounded. Thickness: $4.7 \mathrm{~mm}$ to $6.0 \mathrm{~mm}$. The signs of grinding are evidence of further processing, that has been discussed as a commonly applied technique in glass-making (Komp, 2009, pp. 62f.) and would have impacted the light scattering properties of the glazing.

Striae, ridges, immersions and elevations at the surfaces as result of the production process; air bubbles in the volume, and effects of surface deterioration from wear and chemical corrosion. These features are presumed to effect the light scattering properties of Roman window glass.

Table 1: Find context and dating of the samples.

\begin{tabular}{lllll}
\hline ID & Inventory & Origin & Dating & Type \\
\hline$G 1$ & $\# 9349$ & Blankenheim-Hülchrath, villa rustic & late 1st to end 4th century & matt-smooth \\
$G 2$ & $\# 75.169$ & Dormagen, castellum & end 1st to 4th century & matt-smooth \\
$G 3$ & $\# 70.0459$ & Bonn, castrum & 1st to 5th century & smooth-smooth \\
$G 4$ & $\# 675$ & Bonn, castrum & 1st to 5th century & matt-smooth \\
\hline
\end{tabular}




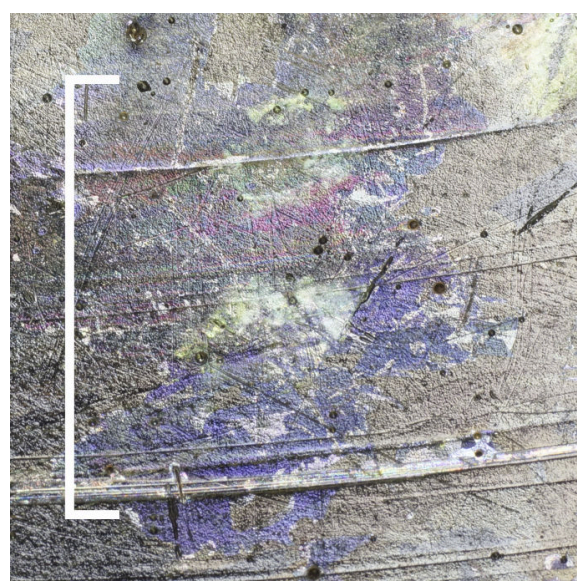

(a)

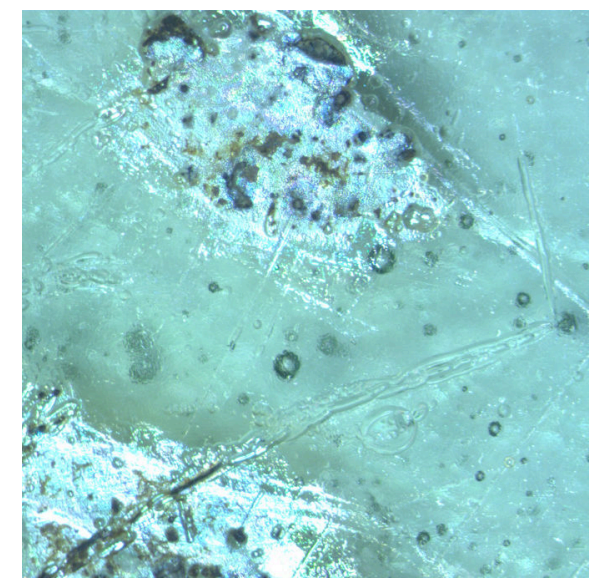

(b)

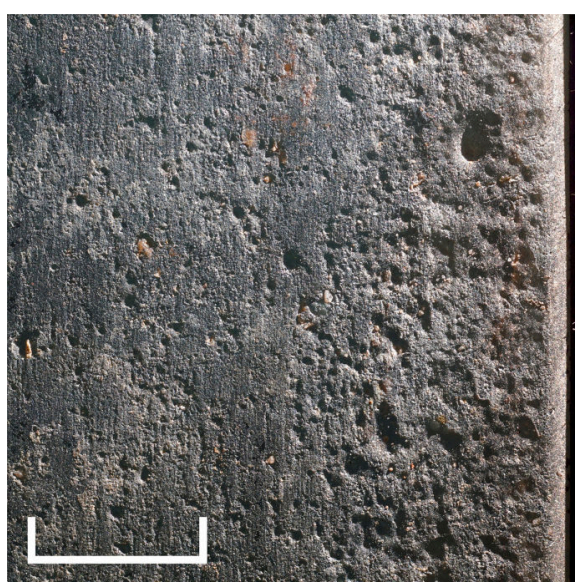

(c)

Figure 4: (a) Iridescent corrosion on sample G3 Noback et al. (2018). The resulting fine roughness of the surface is likely to cause some amount of scattering $(l=10 \mathrm{~mm})$. (b) Areas with inclusions and deeper linear corrosive structures on sample $G 3$ under the microscope. (c) Edge, grinding structure and grains of sand from sample $G 4(l=10 \mathrm{~mm})$.

Table 2: Incident elevation angles $\theta_{i}$ measured for azimuth $\phi_{i}=0^{\circ}$ and all samples.

\begin{tabular}{lll}
\hline ID & $\boldsymbol{\theta}_{\boldsymbol{i}, \boldsymbol{f r o n t}}$ & $\boldsymbol{\theta}_{\boldsymbol{i}, \boldsymbol{b a c k}}$ \\
\hline$G 1$ & $0^{\circ}$ to $70^{\circ}\left(\Delta \theta_{i}=10^{\circ}\right), 75^{\circ}$ & $105^{\circ}, 110^{\circ}$ to $180^{\circ}\left(\Delta \theta_{i}=10^{\circ}\right)$ \\
$G 2$ & $0^{\circ}$ to $70^{\circ}\left(\Delta \theta_{i}=10^{\circ}\right), 75^{\circ}$ & $105^{\circ}, 110^{\circ}$ to $180^{\circ}\left(\Delta \theta_{i}=10^{\circ}\right)$ \\
$G 3$ & $0^{\circ}$ to $60^{\circ}\left(\Delta \theta_{i}=10^{\circ}\right)$ & $130^{\circ}$ to $180^{\circ}\left(\Delta \theta_{i}=10^{\circ}\right)$ \\
$G 4$ & $0^{\circ}$ to $70^{\circ}\left(\Delta \theta_{i}=10^{\circ}\right), 75^{\circ}$ & $105^{\circ}, 110^{\circ}$ to $180^{\circ}\left(\Delta \theta_{i}=10^{\circ}\right)$ \\
\hline
\end{tabular}

\section{Optical characterisation of light scattering}

\subsection{Measurement method and instrumentation}

Measurements were performed on a scanning gonio-photometer Apian-Bennewitz (2010). The instrument comprises an optical bench to illuminate a sample held by a programmable sample mount, and a robotic arm featuring detectors for photometric and radiometric measurements (Figure 5). The incident direction is set by rotation of the sample mount over the vertical axis, and rotation of the holding plate by the sample mount. The outgoing scattered directions are varied by movement of the detector on configurable paths, aimed at the sample.

For this research, a $150 \mathrm{~W}$ Xenon arc-lamp was employed as part of the illuminator. The emitted light is collected by condenser lens $L_{1}$ and a back-mirror, which is integrated in the lamp enclosure. After spatial filtering by pinhole $P H$ (diameter $\approx 2 \mathrm{~mm}$ ), the beam is focused by lens $L_{2}$ on the sample (Figure 6 ).

This configuration of the illuminator was chosen to minimise the size of the sampling aperture $A$. It results in an almost circular, illuminated spot, equal to $A$, that has a diameter of $\approx 8 \mathrm{~mm}$ for normal incidence. The configuration achieves a maximum directional resolution of $\approx 1.5^{\circ}$. With increasing $\theta_{i}, A$ widens to an elliptical shape of width $w=$ $8 \mathrm{~mm} / \cos \theta_{i}$, while the height remains constant $h=8 \mathrm{~mm}$. The increase of $w$ limits the range of incident directions, since it must not exceed the sample's size.

Wooden holding plates were prepared for each sample, utilising a laser cutter to fit the irregular shaped glass fragments to the sample mount. The samples were mounted so that the sampling aperture is located in an area where the sample shows minimum signs of corrosion or other defects (see Figure 3).

Prior to the light scattering measurement, the unobstructed illuminating beam is characterised and the contained power $P_{i}$ is calculated by integration over all outgoing directions. Only after this initial step, the samples are moved into the optical path.

In the course of the measurement, first the incident direction is set (Table 2). Subsequently, the distribution of scattered light is scanned by sampling the detector signal at fixed intervals during the continuous movement of the robotic arm. The detector movement first describes a coarse spherical scan-path. In a subsequent pass, regions where peaks were identified during the first scan are refined. The combination of spherical and peak scans leads to a total of $\approx 400000$ to 500000 data-points per incident direction, including reflection and transmission.

The BSDF for each data-point is computed from the illuminance $E$ recorded by the detector at position $\left(\theta_{s}, \phi_{s}\right)$ 


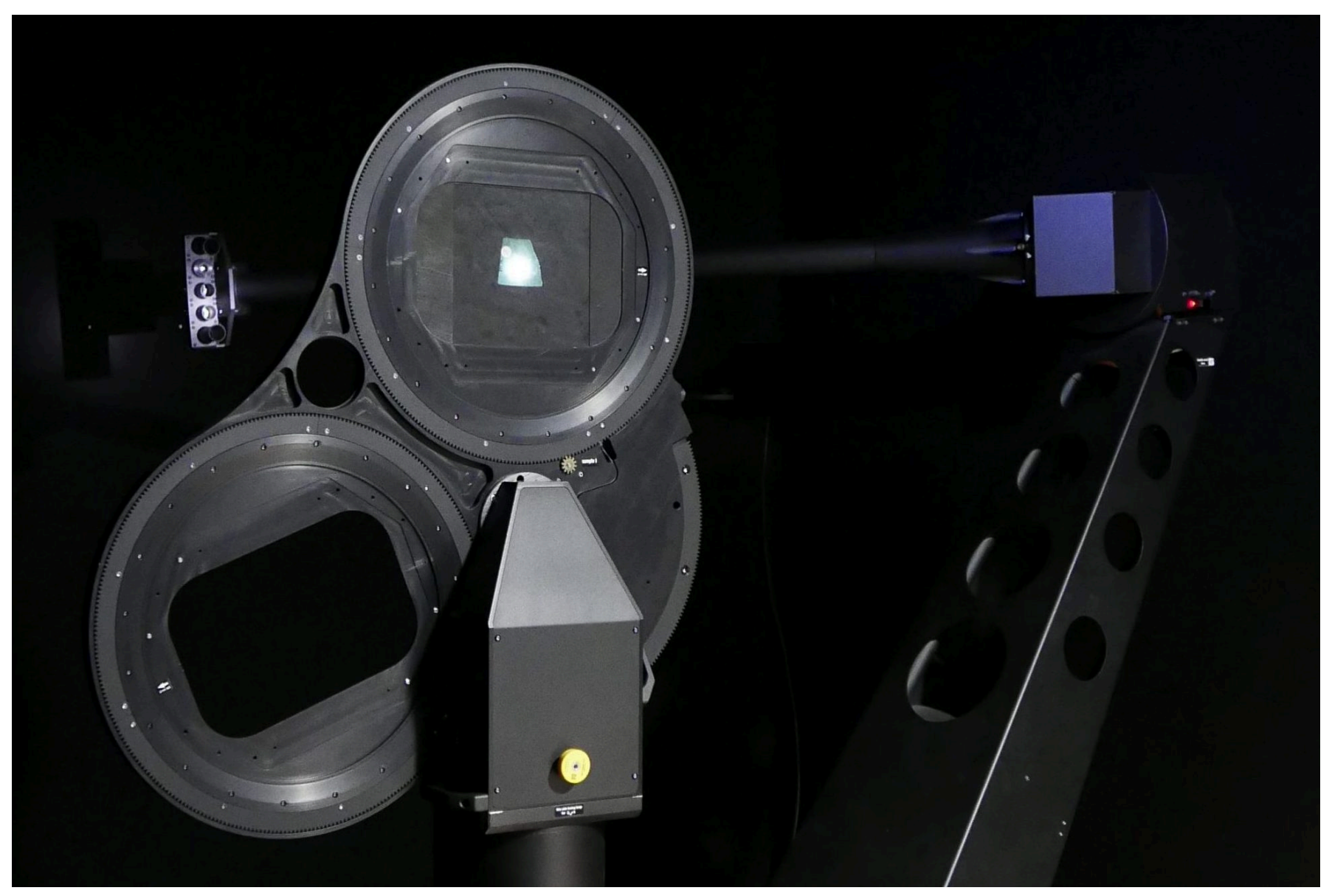

Figure 5: Detector aimed at $G 1$ held by its holding plate in the automated sample mount Grobe (2017).

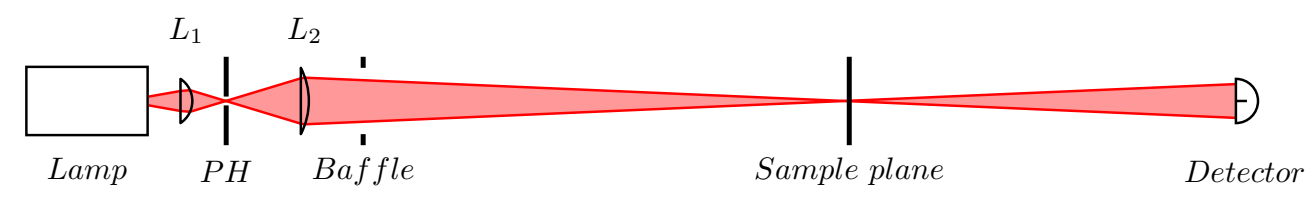

Figure 6: Configuration of the illuminator employed in the BSDF measurements Lee et al. (2018). 
and the beam power $P_{i}$ as (Apian-Bennewitz (1995))

$$
\operatorname{BSDF}\left(\theta_{i}, \phi_{i}, \theta_{s}, \phi_{s}\right)=\frac{E\left(\theta_{i}, \phi_{i}, \theta_{s}, \phi_{s}\right)}{P_{i} \cdot \cos \left(\theta_{s}\right)}
$$

\subsection{Measured optical properties}

Measured light scattering by each of the four samples is illustrated by projections of the transmission hemisphere in Figure 8 (left) for one exemplary incident direction $\theta_{i}=40^{\circ}, \phi_{i}=0^{\circ}$. Shown is the BSDF multiplied by $\cos \left(\theta_{s}\right)$. This reverses the division in Equation 2, since otherwise even low noise would approach infinity at directions close to $\theta_{s}=90^{\circ}$. The full measured data-set is made available for future research Grobe and Noback (2019).

All four samples exhibit a peak due to strong forward transmission, and a diffuse background. However the shape, namely the width, and the intensity of the peaks, as well as the level of the backgrounds differ significantly.

The distinctiveness of the peak primarily affects the clarity of vision and the softness of shadows cast by direct illumination through the glass. The background increases the brightness of the glass itself when exposed to direct sun-light - regardless the view direction. This adds to the ambient illumination of the attached space, and affects vision through and appearance of the glass.

$G 2$ and $G 3$ are similar in that they combine little diffuse scattering with sharp peaks, indicating strong directionality and just little increase of brightness by scattering of direct sun-light.

G1 has a much stronger diffuse background, and the wider peak indicates that incident sun-light is spread over a wider range of directions. The diffuse scattering would significantly increase the brightness of the window when exposed to direct sun-light, giving it a glowing appearance that overlays view through, which is blurred due to the width of the peak.

G4 exhibits the strongest scattering, widening the peak to what could be better describes as a forward lobe, and increasing the diffuse background. The glass can be expected to appear like a bright, translucent surface rather than transparent glazing under direct sun-light.

\section{$5 \quad$ Modelling light scattering based on measurements}

The gonio-photometric measurements provide accurate descriptions of the outgoing distribution of transmitted light only for the selected, measured incident directions. However, a model to be applied in daylight simulation must predict transmission from any direction on the outside to the inside to account for light transport

- from the continuously changing position of the sun,

- from the sky hemisphere, and

- from the ground and the reflective surroundings.

Rather than fitting a mathematical description of light scattering based on a-priori assumptions, the presented research relies on the data-driven BSDF in RADIANCE. The compilation of measured data into the model comprises a sequence of data-processing steps, which are implemented by the commands pabopto2bsdf and bsdf2ttree RADIANCE Grobe et al. (2017); Ward et al. (2012, 2014). Resulting models of the four samples are published alongside this article Grobe and Noback (2019).

\subsection{Fitting measured distributions by radial basis functions}

Each measured distribution is approximated by a set of Gaussian Radial Basis Functions (RBFs). This effectively replaces the high amount of data contained in the high-resolution measurements by a set of few parameters. The RBFs representing all measured transmission data could e.g. generated by the command pabopto2bsdf *_trans.dat $>$ trans.sir.

The accuracy of the algorithm is controlled by a target value of the acceptable relative Mean Squared Error (MSE) ${ }^{1}$. The initial target of 0.03 particularly widened pronounced peaks. Consequently, the differences between the peak shapes of the four samples were eliminated by the RBF approximation. Given the particular importance of the peak shape as an indicator of the clarity of the glass, the target MSE was decreased from 0.03 to 0.005 . The effect of the setting is demonstrated by an overlay of the hull of the RBFs and the the measured outgoing transmission distribution for of sample $G 3$ for $\theta_{i}=30^{\circ}, \phi_{i}=0^{\circ}$ (Figure 7).

\footnotetext{
${ }^{1}$ Defined by SMOOTH_MSE in src/cv/bsdfrbf.c.
} 


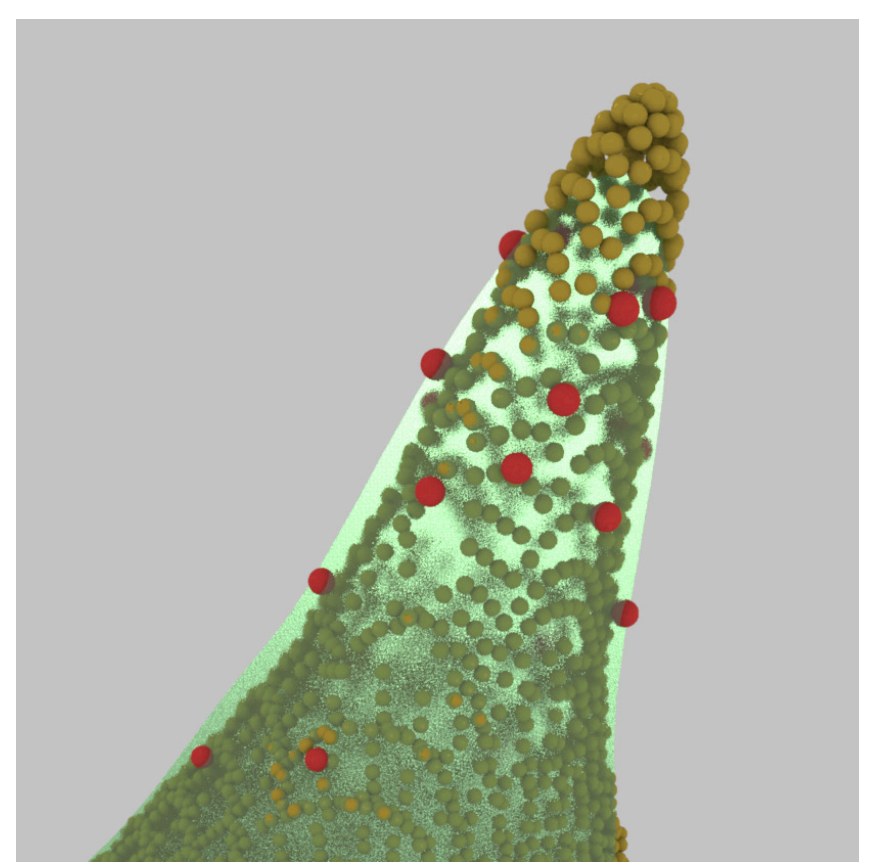

(a)

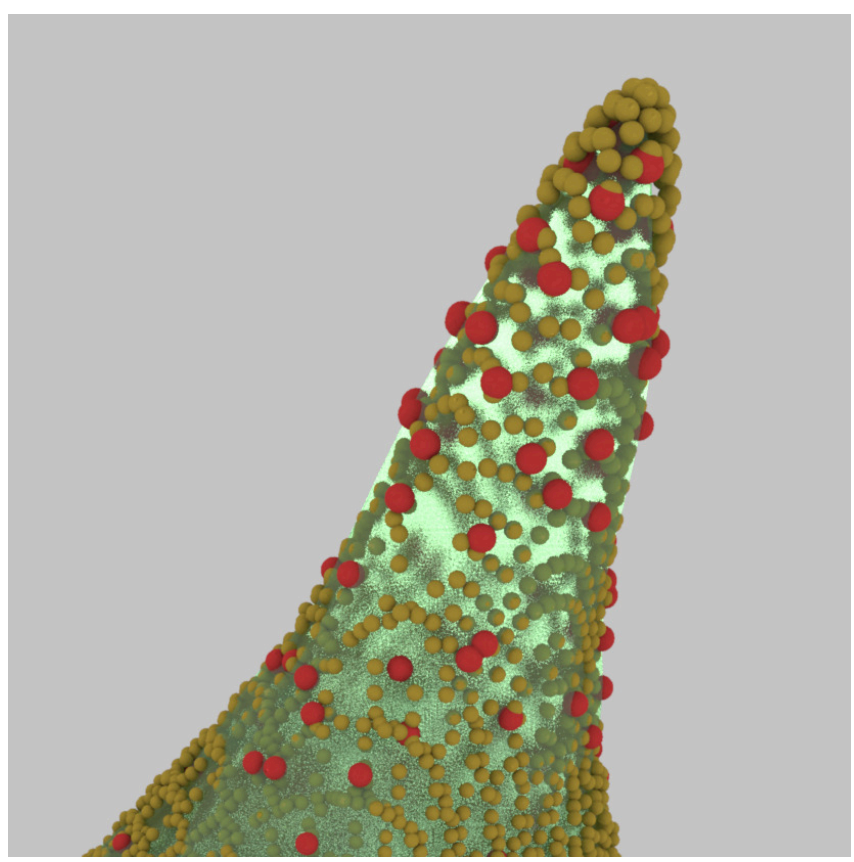

(b)

Figure 7: Transmitted peak through $G 3, \theta_{i}=30^{\circ}$ (logarithmic scale). Decreasing the target MSE from 0.03 (a) to 0.005 (b) increases the number of RBFs in the model (directions indicated by red spheres), and improves the accordance of the RBFs' hull (green surface) with the measured data-points (yellow spheres).

\subsection{Interpolation and sampling}

The RBF representations are grouped to form four geometric BSDF components front-reflection, front-transmission, back-reflection and back-transmission according to the attribution of incident and outgoing directions to the inside or outside of the sample.

The interpolation of distributions itself poses a particular challenge. A naive, linear interpolation of two distributions with a directly transmitted peak would e.g. modulate the height of the two peaks at their initial location rather than moving the peak. RADIANCE addresses this challenge by the application of an advanced mass-transport algorithm Bonneel et al. (2011).

The interpolated BSDF is discretised according to a given target resolution, and stored in a three-dimensional data-cube $^{2}$. In a subsequent pass, the directional resolution of the data-set is reduced by merging adjacent cells in regions of low variance until a given data-reduction target is reached.

For this research, an initial angular resolution of $\approx 0.7^{\circ}$ led to a data cube of $2^{8} \times 2^{8} \times 2^{8}$ elements, which was then reduced by $95 \%$. Discretisation and data-reduction were achieved by the command bsdf 2 ttree -g 8 -t 95 trans.sir > trans.xml.

The BSDFs predicted by the resulting models of all four samples for $\theta_{i}=40^{\circ}, \phi_{i}=0^{\circ}$ are contrasted with the corresponding measurements in Figure 8.

\section{Simulating the effects of light scattering}

\subsection{Setup of simplified test scene to compare glazing properties}

The four glass models were applied in a simplified architectural scene. The scene comprises a room on quadratic plan, featuring a groin vault and a simplified Diocletian window oriented East (Figure 10(a)). Daylight simulations were performed with each glass model (G1-G4) applied to the window's glass panes (Figure 10(c)-(f)), and without any panes as reference (Figure 10(b)). Walls, floor and vault are equally set to ideally Lambertian reflectance $\rho=0.40^{3}$. The scene has been designed to evaluate the effect of the window's scattering properties on the appearance of the window and opaque surfaces exposed to directly transmitted sunlight.

The scene is lit by a standard International Commission on Illumination (CIE) sunny sky model ISO 15469:1997 (1997), configured for mid morning on a spring day close to Equinox. Combined with the orientation of the window, these settings provide a patch of sunlight on the Northern wall and allows light to be scattered toward the observer.

\footnotetext{
${ }^{2}$ This assumes isotropic scattering. To replicate anisotropic scattering, the data-structure would become a tensor of four dimensions.

${ }^{3}$ The value approximates the mean total reflection measured by the authors on different marble or stone wall cladding common in Roman architecture.
} 

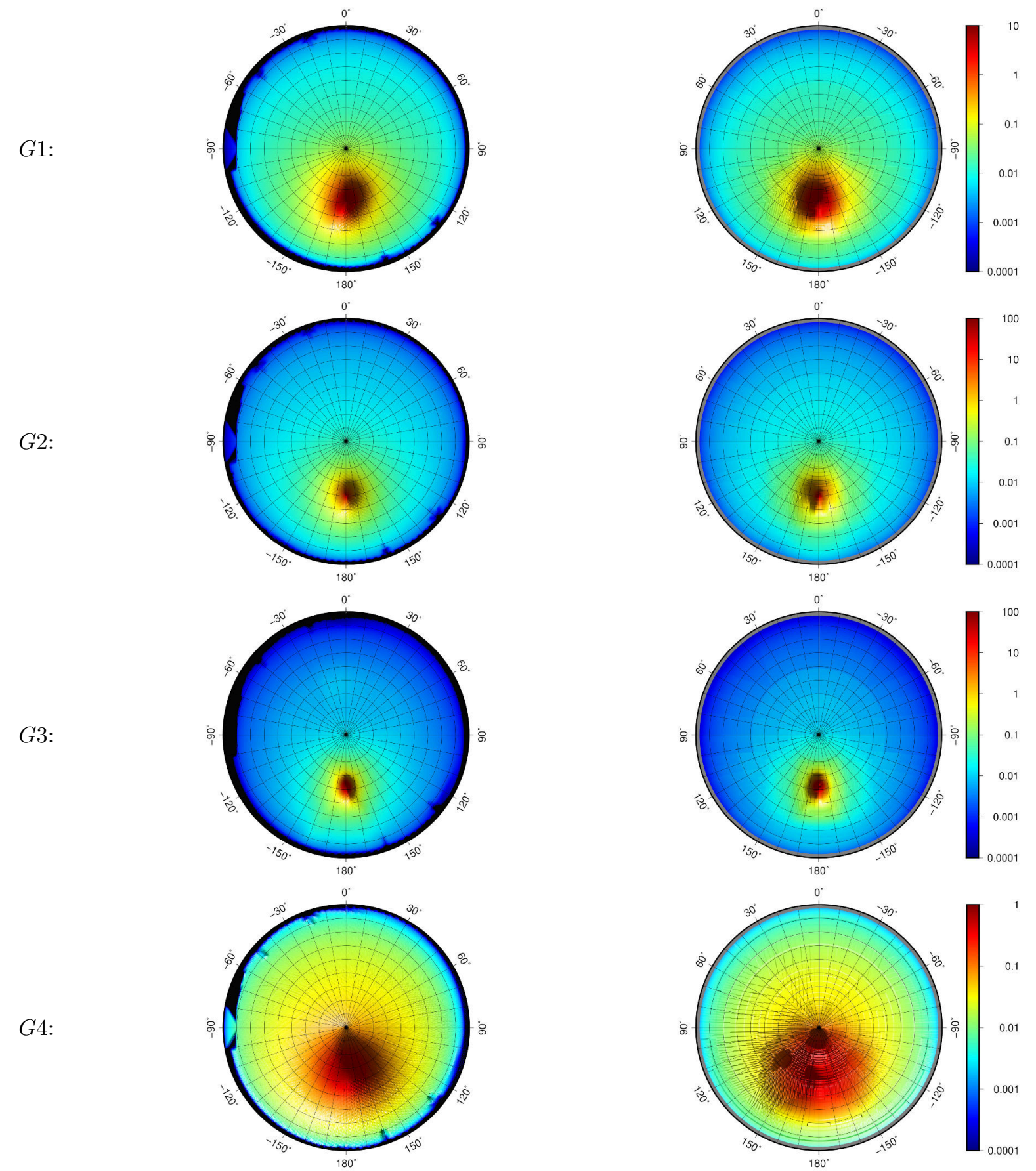

Figure 8: Measured BSDFs (left) and data-driven models (right) for incident direction $\theta_{i}=40^{\circ}, \phi_{i}=0^{\circ}$ Noback et al. (2018). Note that in-plane angles $\phi$ are reversed for the models. 


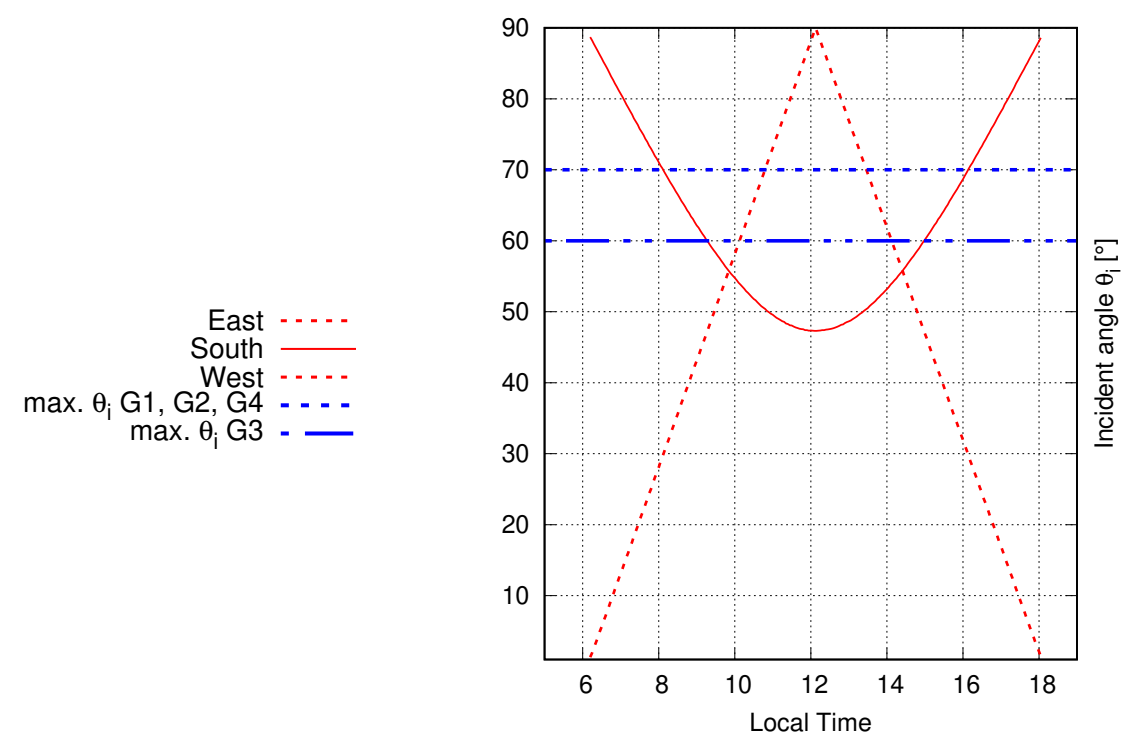

Figure 9: Incident angle $\theta_{i}$ for windows facing East, West and South at March 20th (Equinox). The validity of the models $G 1, G 2$ and $G 4$ of $\max . \theta_{i}=70^{\circ}$ resp. $G 3$ of max. $\theta_{i}=60^{\circ}$ is exceeded at multiple times of day.

This solar geometry ensures that the incident angle of sunlight $\left(\theta_{i}=40.7^{\circ}\right)$ relative to the glass surface is within the valid range of the models $\left(\theta_{i}<60^{\circ}\right.$ for $G 3, \theta_{i}<75^{\circ}$ for the other samples). ${ }^{4} \theta_{i}$ can be calculated from the solar Zenith angle $Z_{\text {sun }}=90^{\circ}-e$ and $\Gamma$ for an East-oriented window (slope $\omega=90^{\circ}$, azimuthal rotation toward West from South $\gamma=-90^{\circ}$ ) according to Equation 3 Reda and Andreas (2008):

$$
\theta_{i}=\arccos \left(\cos \left(Z_{\text {sun }}\right) \cos (\omega)+\sin (\omega) \sin \left(Z_{\text {sun }}\right) \cos (\Gamma-\gamma)\right)
$$

The RADIANCE command gensky is parameterised by the solar elevation angle $e$ (measured from the horizon) and the topocentric astronomers azimuth angle $\Gamma$ (in RADIANCE measured toward West from South). According to the chosen solar geometry with $e=29.9^{\circ}, \Gamma=-57.4^{\circ}$, the sky model was generated by gensky -ang $29.9-57.4$. The sky model calculates the sky luminance depending on the direction and features a diffuse ground reflection that was set to $\rho=0.20$. The colours of sun, sky and ground were set to white, blue and beige respectively to distinguish their contributions to the illumination of the room.

The simulations were conducted utilising backward ray-tracing as implemented in RADIANCE, and were controlled by the program rad. To minimise artefacts due to the stochastic sampling as part of the indirect-diffuse calculation, parameters Variability and Quality were set to High. Given the simplified model geometry, the Detail parameter was set to Low. The diffuse-indirect calculation was limited to three reflection steps. ${ }^{5}$

\subsection{Luminance ratios and imagery to compare the effect of light scattering}

For each of the rectangular image regions marked in Figure 10(b), the average luminance were extracted from the imagery. The ratio of the the average luminance in the directly illuminated image region A over that in the diffusely illuminated region $\mathrm{B}$ on side-wall was evaluated as $\bar{L}_{A} / \bar{L}_{B}$. The ratio of region $\mathrm{C}$, covering parts of the glazing, over the diffusely illuminated region on the window wall D, was calculated accordingly as $\bar{L}_{C} / \bar{L}_{D}$. All luminance averages and their ratios are reported in Table 3.

The pixel values in the images resulting from the simulation are in units of luminance. These are photometrically valid representations of the light distribution within the field of view, but do not correspond to the visual perception by a human observer. To approximate the latter, from each luminance map an image was generated with the RADIANCE program pcond. The software implements a perception model, that mimics aspects of human vision such as contrast reduction and glare from bright light sourcesWard Larson et al. (1997) (Figure 10). The resulting pictures simulate the perception of the scene by an observer with vision adapted to its brightness and contrast.

\subsection{Effects of the four samples on the illumination of the test scene}

Four renderings in Figure 10(c)-(f) show the impact of the different light scattering properties of samples G1 to G4 on visual perception. The view is identical to that of the reference image without glass in Figure 10(b). The luminance

\footnotetext{
${ }^{4}$ Since isotropic transmission models were used, $\phi_{i}$ was not considered.

${ }^{5}$ Resulting in the following rpict parameters: -dp 1024 -ar 31 -ms 0.1 -ds .2 -dt 0.05 -dc 0.75 -dr 3 -ss 16 -st 0.01 -ab 3 -af scene.amb -aa 0.075 -ad 4096 -as 2048 -av 0.50 .50 .5 -lr 12 -lw 1e-5 -ps 8 -pt 0.04.
} 


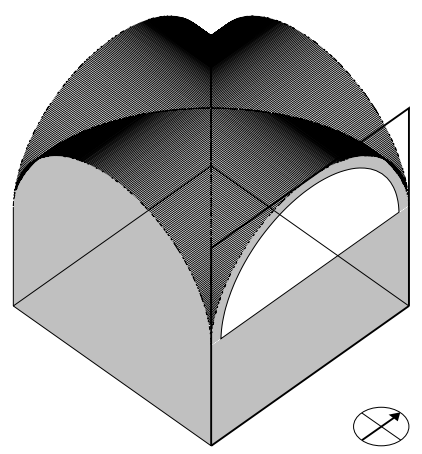

(a)

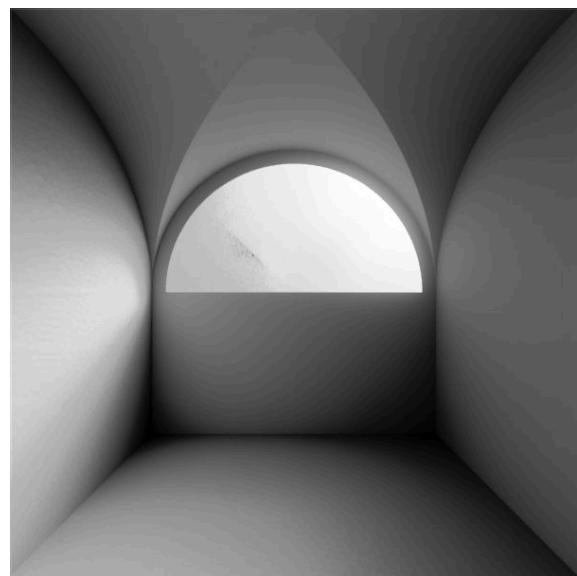

(d)

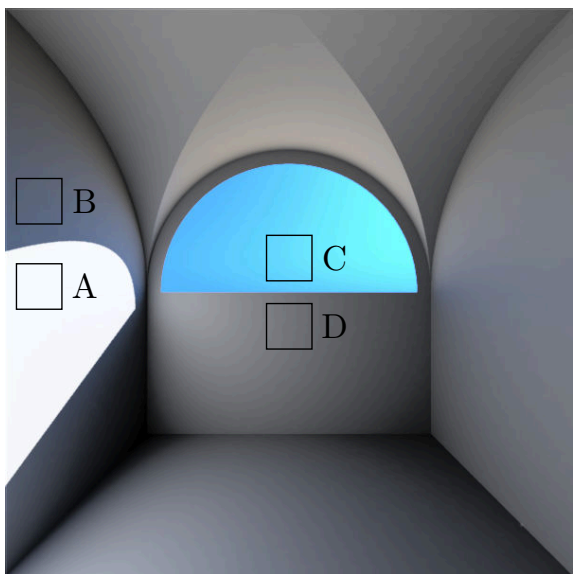

(b)

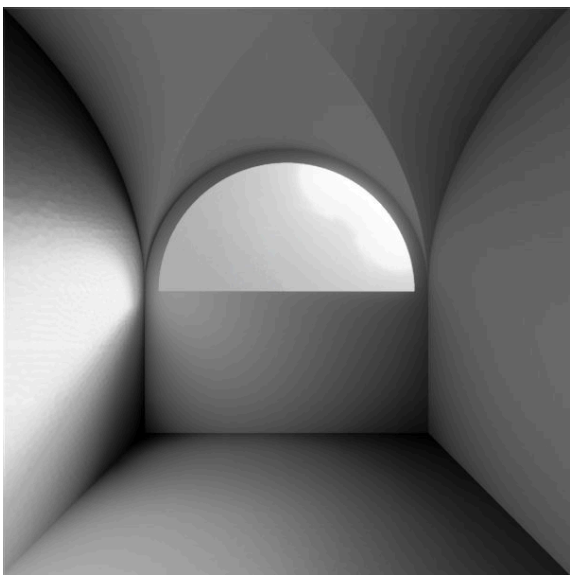

(e)

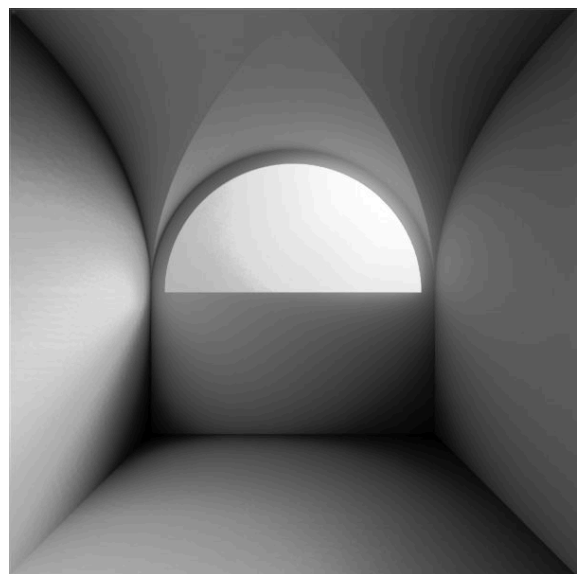

(c)

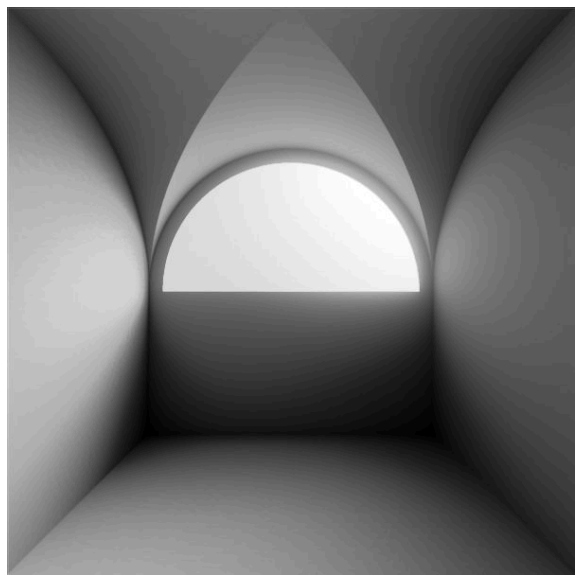

(f)

Figure 10: The test scene: (a) Geometric model of the test scene with its East-facing window. (b) Reference scene without glazing, rectangular areas A to D as used in the calculation of luminance ratios. (c)-(f) Renderings of the test scene with models G1-G4. The renderings mimic human visual response: it adapts to the contrast and brightness of the individual scene. This allows to compare the impression on the scene on printed paper, but not the comparison of brightness values from one setup to another. 

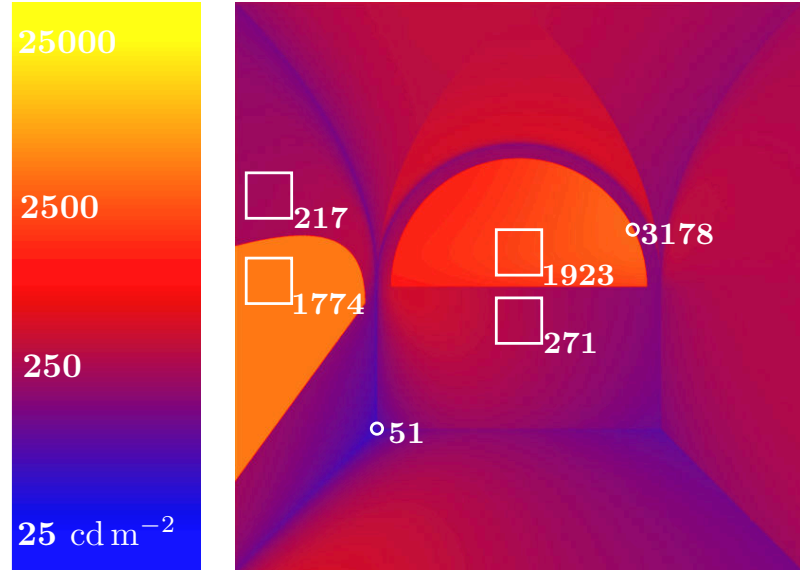

(a)

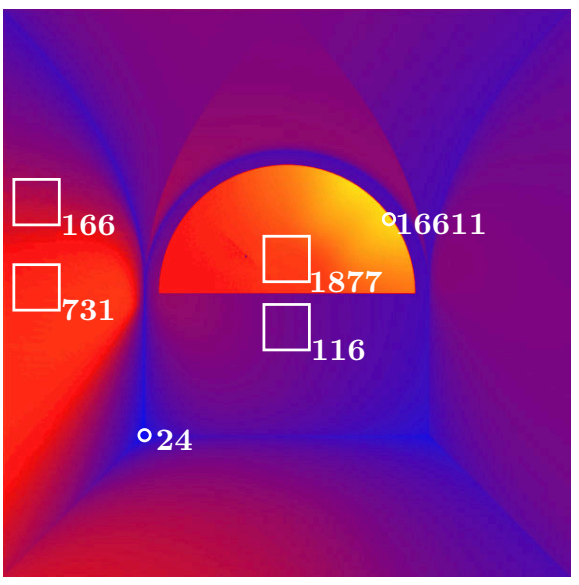

(c)

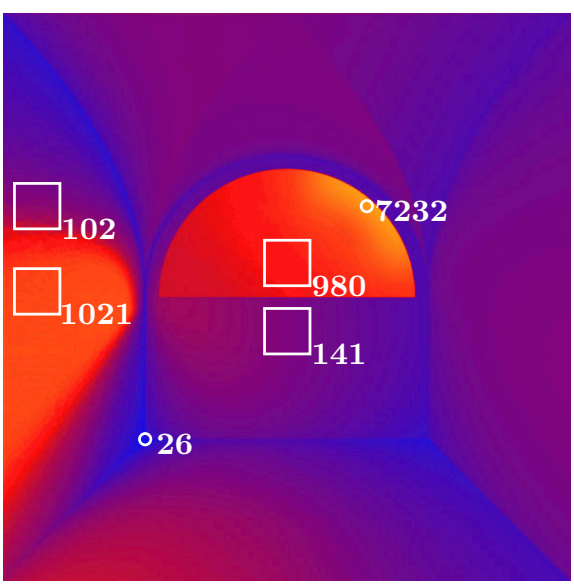

(d)

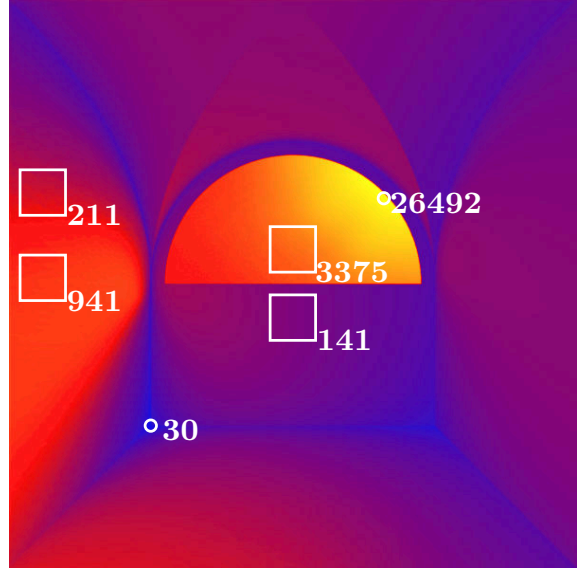

(b)

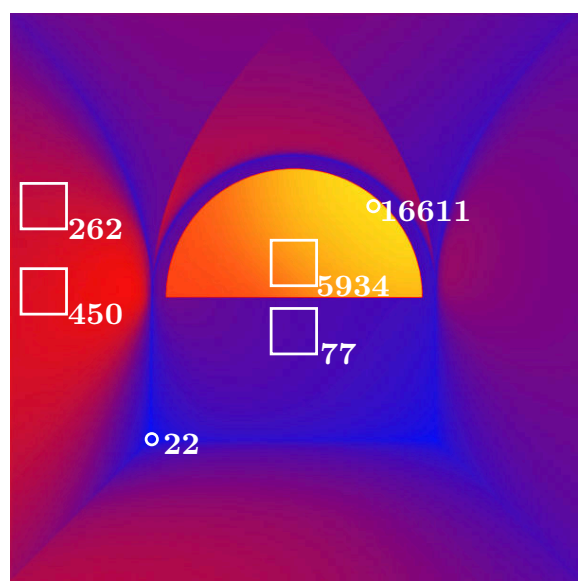

(e)

Figure 11: Luminance distributions in the test scene by reference (a) and models $G 1$ to $G 4$ (b)-(e) (logarithmic scale). Maximum and minimum values at their respective locations (circles) and average luminance for regions A-D (squares). 
Table 3: Luminance averages and ratios on side-wall $\left(\bar{L}_{A}, \bar{L}_{B}\right)$ and window-wall $\left(\bar{L}_{C}, \bar{L}_{D}\right)$.

\begin{tabular}{lcccccc}
\hline ID & $\begin{array}{c}\overline{\boldsymbol{L}}_{\boldsymbol{A}}(\mathrm{Patch}) \\
{\left[\mathrm{cd} \mathrm{m}^{-2}\right]}\end{array}$ & $\begin{array}{c}\overline{\boldsymbol{L}}_{\boldsymbol{B}} \text { (Wall) } \\
{\left[\mathrm{cd} \mathrm{m}^{-2}\right]}\end{array}$ & $\begin{array}{c}\overline{\boldsymbol{L}}_{\boldsymbol{A}} \\
\overline{\boldsymbol{L}_{\boldsymbol{B}}}\end{array}$ & $\begin{array}{c}\overline{\boldsymbol{L}}_{\boldsymbol{C}} \text { (Window) } \\
{\left[\mathrm{cd} \mathrm{m}^{-2}\right]}\end{array}$ & $\begin{array}{c}\overline{\boldsymbol{L}}_{\boldsymbol{D}} \text { (Wall) } \\
{\left[\mathrm{cd} \mathrm{m}^{-2}\right]}\end{array}$ & $\begin{array}{c}\overline{\boldsymbol{L}}_{\boldsymbol{C}} \\
\overline{\boldsymbol{L}}_{\boldsymbol{D}}\end{array}$ \\
\hline Reference & 1774 & 217 & 8.18 & 1923 & 271 & 7.10 \\
$G 1$ & 941 & 211 & 4.46 & 3375 & 141 & 23.90 \\
$G 2$ & 731 & 166 & 4.40 & 1877 & 116 & 16.12 \\
$G 3$ & 1021 & 102 & 10.00 & 980 & 141 & 6.93 \\
$G 4$ & 450 & 262 & 1.72 & 5934 & 77 & 77.36 \\
\hline
\end{tabular}

distributions are visualised in Figure 11. The corresponding luminance averages of the image regions A to D, and their ratios, are listed in Table 3.

Reference: No glazing. In the reference rendering without glazing, the brightest luminance values in the scene can be found within the sky $\left(\bar{L}_{C}\right)$ closely followed by values in the patch of sunlight on the wall on the left $\left(\bar{L}_{A}\right)$. This patch has sharp edges resulting in a high luminance ratio $\bar{L}_{A} / \bar{L}_{B}$. The luminance ratio $\bar{L}_{C} / \bar{L}_{D}$ of window and the wall beneath is similarly high. The colours in the vaults show that ground reflection contributes to their illumination. Blue light from the sky illuminates the walls and the floor ${ }^{6}$. The visual result would be similar in a scene with modern glazing.

G1: Formed window glass with leather-like structure. The luminance values in the window $\bar{L}_{C}$ in this scene are more than three times higher than in the light-patch and the luminance ratio $\bar{L}_{C} / \bar{L}_{D}$ is much higher than in the reference. The window lights up in the sunlight. The edges of the light-patch are completely blurred resulting in a significantly reduced luminance ratio $\bar{L}_{A} / \bar{L}_{B}$. The vaults appear similar to the reference.

G2: Formed window glass with flat lower side. This scene shows similarities to $G 1$ with similar luminance ratios but lower absolute values. The blurring of the edges of the light patch is a little bit less distinct and the luminance ratio $\bar{L}_{C} / \bar{L}_{D}$ is a little bit lower.

G3: Blown window glass. Although the illumination of the scene can be clearly distinguished from the reference, the blown window glass results in less blurring than the formed glass types. The window does not significantly light up in the sunlight. Luminance values and ratios reflect that and are similar to the reference. ${ }^{7}$

G4: Formed window glass with sings of grinding. The luminance values in the window $\bar{L}_{C}$ in this scene are more than ten times higher than in the light-patch and the luminance ratio $\bar{L}_{C} / \bar{L}_{D}$ is much higher than for the other glasses. The window lights up brightly in the sunlight. The light-patch can not be distinguished form the surrounding luminance of the wall. The luminance ratio $\bar{L}_{A} / \bar{L}_{B}$ is significantly reduced. The vaults are brighter than in the other scenes as they receive scattered sunlight from the window.

\section{Discussion}

\subsection{Samples}

All samples show signs of corrosion that affects the glass surfaces and thereby the scattering of light. Since the combined effects of manufacturing and ageing were measured, it is not possible to isolate the latter, to eliminate it from the result, or to estimate its impact. Consequently, the presented characterisation and data-driven models do not reflect the original conditions of the samples, but include effects of glass-making techniques as well as the subsequent deterioration of the artefact during and after its use until excavation, cleaning and processing of the archaeological find, and any later reactions with its environment.

Most of the samples show uneven thickness so that the surfaces are not parallel to each other and light is refracted. $G 1$ shows remains of mortar, $G 3$ and $G 4$ wrought edges. All four samples are probably from the edges of window panes. The centre of a window pane is expected to be thinner and therefore might show less scatter from air inclusions. This implies that the samples, and therefore the measurements, are not necessarily representative for entire window panes.

\subsection{Measurements}

The distinct visible features of the sample that can be attributed to the two manufacturing techniques affect light scattering. $G 3$, the only example of blown window glass in this research, exhibits the strongest directionality, reflected by a strong peak in the distributions, and little diffuse transmission. The three formed glass fragments significantly differ in their light scattering properties. All formed glasses have a higher diffuse background than the blown glass,

\footnotetext{
${ }^{6}$ The generated BSDF models do not effect the colour of transmitted light, therefore the renderings with the glass models appear grey.

${ }^{7}$ The reduced contrast between the intersecting barrels vaults in this rendering can be attributed to the high incident angles of the light reflected from the ground. These angles are outside the valid range of this model.
} 
but very different peak shapes. The results indicate the diversity of Roman window glass in terms of scattering of directional transmission, and diffuse transmission, characteristics closely related to clarity and haze.

\subsection{Modelling and simulation}

The test scene illustrates the characteristic differences between the four evaluated samples. Effects by opaque surfaces were deliberately minimised. For similar reasons, the CIE clear sky was chosen as an extreme sky condition. It helps to isolate scattering by the different kinds of window glass from the gradual change of diffuseness of incident light defined by the sky model. Such nuances would be better replicated by the current, extended set of CIE skies ISO 15469:2004 (2004), or the parametric sky model by Perez Perez et al. (1990). The latter is parametrised by commonly available, monitored weather-data, making it the de-facto standard in daylight simulations in building sciences. In historical sciences, this tight link to empirical data however becomes problematic due to the lack of historical records. The deliberate use of synthetic models, e.g. the CIE skies, therefore seams to be preferable unless propositions on the luminous conditions at a particular point in time in history can be justified. For the same reason, data-driven techniques such as image based lighting Debevec (2005); Mehlika (2013) can only simulate a modern sky condition, but cannot reconstruct the luminous conditions in the distant past.

The use of a monochromatic sky model supports the differentiation between diffuse sky-light (blue in the exemplary simulations) and direct sun-light (white). This reflects the focus of this research on light scattering, e.g. the spatial distribution of light. Consequently, the interior surfaces of the test scene, and the data-driven BSDF models, are grey. Spectrally resolved sky models, e.g. extensions of the Perez model that are frequently employed in computer graphics Preetham et al. (1999); Hosek and Wilkie (2012), would provide more realistic imagery and allow to study the effects of emitted light, transmission and reflection on colour perception. The method in principle supports the acquisition and modelling of coloured BSDF.

RADIANCE and its data-driven BSDF model have proved of value for the given task, but require careful setting of parameters that are of utter importance for the validity of the results as well as the computational effort. The authors relied on the backward ray-tracing algorithm for the exemplary light simulations. This required to refine the parametrisation of the indirect-diffuse (or ambient) calculation to ensure the adequate sampling of the high-resolution BSDF models. The bidirectional photon mapping algorithm, also implemented in RADIANCE, would lend itself as an alternative in simulations with models of higher complexity.

Compared to the reference Figure 10(b), all models of Roman glass significantly affect the illumination of the test scene (Figure 10). This is reflected by the luminance averages, and their calculated ratios as reported in Table 3 . The effects on image regions differs for the evaluated glasses. For the side wall, it is $G 3$ that stands out from all samples due to its strong directional transmission, resulting in a luminance ratio $\bar{L}_{A} / \bar{L}_{B}=10.00$ compared to 1.72 to 4.46 for the other samples. On the window wall, it is $G 4$ that achieves an outstanding $\bar{L}_{C} / \bar{L}_{D}=77.36$ compared to 6.93 to 23.90 for the others. These luminance rations reflect the two apparent key aspects of directionality and diffuse background, that can be observed directly in the BSDF measurements in Figure 8.

\section{Conclusions, limitations and further research}

\subsection{Samples}

The main challenge in the development of data-driven models, if originating from measurements on archaeologic finds, is to address the effects of deterioration that are inherent in the empirical data. The translation of the measured properties of archaeologic finds into simulation models inevitably includes effects by damage and age. If the objective of modelling is to reconstruct past conditions, these effects need to be eliminated. Further research is required to distinguish between the sources of scatter and to reconstruct the original optical characteristics without deterioration. This is of special importance in the case of blown glass panes, where corrosion might significantly contribute to the total amount of scatter.

To generate a representative model, e.g for an entire window pane, or the average optical properties of window panes originating from a given manufacturing technique, a larger amount of samples would be required. This research aims at the development and demonstration of a modelling method rather than representative results. The set of samples combines the predominant manufacturing techniques with typical deterioration effects. Only few samples from a limited area, which are not attributed to a particular architectural context, were characterised. Further research is necessary to generalise the results and to investigate other types of Roman window glass.

\subsection{Measurements}

The measurements are ample to generate valid material models for a limited range of cases, and accurately describe light scattering by the different samples, beyond what can be distinguished by visual inspection. Besides the presented application in the generation of models, the measured BSDF may also provide valuable information to identify effects by e.g. production techniques and ageing of the samples. 
While the measurements led to accurate models for the range of incident directions included in the measurement, BSDF data closer to grazing angles is necessary to generate models of universal use. A reasonable limit for this would be e.g. $\theta_{i} \approx 82^{\circ} 8$. However, with the current setup, this results in an elliptic sampling aperture of $8 \mathrm{~mm} \times 80 \mathrm{~mm}$ that effectively exceeds the size of most available samples. Direct light from grazing angles $\theta_{i}>82^{\circ}$ is occluded by window frames or embrasures in typical architectural contexts and transmission decreases due to the increased reflection on glass interfaces for angles close to grazing.

\subsection{Modelling and simulation}

The method is applicable to the study Roman window glass. Light scattering, as predicted by the data-driven models, alters the lighting of the scene significantly. This implies a clear distinction from daylighting with modern glazing. It further implies the importance of production methods for the lighting of Roman interiors. The model derived from the blown glass sample differs significantly from all others. Nevertheless the formed glass models have own distinct lighting characteristics. For the latter, the window effectively becomes an area light source in itself with significant visual importance. It may introduce glare and results in a more evenly light distribution over the scene's surfaces. The application of the blown glass model for-mostly blurs the edges of the patch of sunlight and reduces the contrast over the northern wall significantly. The distinctness of this effect may be reduced for a glass in its original state without corrosion. Nevertheless the effect is of visual importance.

\subsection{Outlook}

The scattering characteristics of the glazing material are a relevant factor for the lighting of Roman architecture. This correlation asks for thorough research. It relates to many aspects of interior architecture: marble decoration, wall painting or mosaics etc. It relates to lighting concepts and the architectural staging of performative enactment. The transition in the usage from formed to blown window glass since the end of the 2nd century (Komp (2009) p. 69, Arletti et al. (2010)) relates to a significant change in lighting of Roman architecture. The results clearly call for further study, especially for real architecture as test cases.

To extend the range of incident directions, that can be measured on small glass fragments, other light sources achieving a smaller sampling aperture, e.g. lasers emitting in the wavelength range of visible light, are currently evaluated. The modified setup shall be applied in the characterisation of a larger set of samples to estimate the bandwidth of light scattering properties for a particular site and production period.

To eliminate the impact of damages and age in data-driven modelling, two approaches are currently investigated. One is the temporary healing of surface defects by restorative measures. The other possible strategy is to prepare physical replicates, employing techniques from experimental archaeology, or to model the detailed geometry of the glass structures and derive the BSDF by computational means. Preparation of these intermediate, physical or digital models, would still have to be guided by accurate characterisation of findings.

\section{Acknowledgements}

The authors express their gratitude to LVR-LandesMuseum (Bonn) for providing the samples, and in particular to Dr. Jennifer Komp for her expert support in selecting and analyzing the glass finds. We thank Dr. Susanne Greiff from the Römisch-Germanisches Zentralmuseum (Mainz) for her contribution to the characterisation of the state of preservation and the identification of traces of processing on the samples. This includes the micro photography of Figure 4(b). Greg Ward guided us in the improved parametrisation of the basis functions to our measurements when generating the data-driven model.

This research, as part of the pilot study "Messung und Simulation der Streuung von Tageslicht an römischen Fenstergläsern", was funded by the Fritz Thyssen Stiftung für Wissenschaftsförderung, Köln (Az.20.18.0.006AA).

\section{References}

Denise Allen. 2002. Roman window glass. In Artefacts and archaeology. Aspects of the Celtic and Roman world, Miranda Jane Aldhouse-Green and Peter Webster (Eds.). University of Wales Press, Cardiff, UK, $102 \mathrm{ff}$.

Peter Apian-Bennewitz. 1995. Messung und Modellierung von lichtstreuenden Materialien zur Computer-Simulation von Tageslichtbeleuchtung. Ph.D. Dissertation. Albert-Ludwigs-Universität, Freiburg, DE.

Peter Apian-Bennewitz. 2010. New scanning gonio-photometer for extended BRTF measurements. In SPIE Optical Engineering + Applications, Vol. 7792 Reflection, Scattering, and Diffraction from Surfaces II. International Society for Optics and Photonics, Brussels, BE, 77920O-77920O. https://doi.org/10.1117/12.860889

\footnotetext{
${ }^{8}$ In building science, an established directional basis includes directions up to $82.5^{\circ}$.
} 
Peter Apian-Bennewitz and Jochen von der Hardt. 1998. Enhancing and calibrating a goniophotometer. Solar Energy Materials and Solar Cells 54, 1-4 (1998), 309 - 322. https://doi.org/10.1016/S0927-0248(98)00082-8

R. Arletti, G. Vezzalini, S. Benati, L. Mazzeo Saracino, and A. Gamberini. 2010. Roman window glass: A Comparison of findings from three different Italian sites. Archaeometry 52, 2 (2010), 252-271. https://doi.org/10.1111/j . $1475-4754.2009 .00479 . x$

ASTM E2387-05 2011. Standard practice for goniometric optical scatter measurements. Standard ASTM E2387-05. ASTM / SC E12.03. https://doi.org/10.1520/E2387-05R11

Dietwulf Baatz. 1991. Fensterglas, Glasfenster und Architektur. In Bautechnik der Antike. Diskussionen zur Archäologischen Bauforschung, Vol. 5. Philipp von Zabern, Darmstadt, $4 \mathrm{ff}$.

Martin Bachmann. 2011. Fenster zum Hof. Zur Belichtungsfrage pergamenischer Peristylhäuser. In Licht - Konzepte in der vormodernen Architektur. Schnell \& Steiner, Regensburg, 128-141.

Nicolas Bonneel, Michiel Van De Panne, Sylvain Paris, and Wolfgang Heidrich. 2011. Displacement interpolation using Lagrangian mass transport. ACM Transactions on Graphics (TOG) 30 (2011), 158. Issue 6. https://doi.org/ $10.1145 / 2070781.2024192$

Remi Cerise, Fernando da Graça, Frederic Magoulès, and Patrick Callet. 2012. Natural lighting and medieval glass Scientific data acquisition, methodology and physically based rendering. In Progress in cultural heritage preservation EuroMed 2012 (Lecture Notes in Computer Science), Marinos Ioannides, Dieter Fritsch, Johanna Leissner, Rob Davies, Fabio Remondino, and Rossella Caffo (Eds.), Vol. 7616. Springer, Limassol, Cyprus, 636-643. https: //doi.org/10.1007/978-3-642-34234-9_66

Paul Debevec. 2005. Making T̈he Parthenon: In 6th International Symposium on Virtual Reality, Archaeology, and Cultural Heritage.

Jörg Drauschke and Susanne Greiff. 2008. Chemical aspects of Byzantine glass from Caričin Grad / Iustiniana Prima (Serbia). In Glass in Byzantium - Production, usages, analyses (RGZM - Tagungen), Jörg Drauschke and Daniel Keller (Eds.). Verlag des Römisch-Germanischen Zentralmuseums, Mainz, DE, 25-45.

Graeme Earl, Vito Porcelli, Constantinos Papadopoulos, Gareth Beale, Matthew Harrison, Hembo Pagi, and Simon Keay. 2013. Formal and informal analysis of rendered space: The Basilica Portuense. In Computational approaches to archaeological spaces, Andrew Bevan and Mark Lake (Eds.). Left Coast Press, Walnut Creek, CA, Chapter 11, 265.

Souen Deva Fontaine and Danièle Foy. 2008. Diversité et évolution du vitrage de l'Antiquité et du haut Moyen Âge : un état de la question. Gallia 65, 1 (2008), 405-459. https://doi.org/10.3406/galia.2008.3349

Ian C. Freestone, Michael J. Hughes, and Colleen P. Stapleton. 2008. The composition and production of Anglo-Saxon glass. In Catalogue of Anglo-Saxon glass in the British Museum, Vera I. Evison and Sonja Marzinzik (Eds.). The British Museum, London, UK, 29-46.

David Geisler-Moroder and Arne Dür. 2010. A new Ward BRDF model with bounded albedo. Computer Graphics Forum 29 (2010), 1391-1398. Issue 4. https://doi.org/10.1111/j.1467-8659.2010.01735.x

E. Gliozzo, A. Santagostino Barbone, and F. D'Acapito. 2013. Waste glass, vessels and window-panes from Thamusida (Morocco): Grouping natron-based blue-green and colourless Roman glasses. Archaeometry 55, 4 (2013), 609-639. https://doi.org/10.1111/j.1475-4754.2012.00696.x

Lars Oliver Grobe. 2017. Daylighting in the antique. https://blog.hslu.ch/solarcontrol/2017/05/30/ daylight-performance-of-antique-roman-glazing

Lars Oliver Grobe. in press. Photon mapping to accelerate daylight simulation with high resolution, data-driven fenestration models. Journal of Physics: Conference Series CISBAT 2019 (in press).

Lars Oliver Grobe and Andreas Noback. 2019. Light scattering by Roman window glass. https://doi.org/10. 5281/zenodo.3265014 Digital data-set.

Lars Oliver Grobe, Stephen Wittkopf, and Zehra Tuğçe Kazanasmaz. 2017. High-resolution data-driven models of daylight redirection components. Journal of Facade Design and Engineering 5 (2017), 101-113. https://doi. org/10.7480/jfde.2017.2.1743

Jassim Happa, Tom Bashford-Rogers, Alexander Wilkie, Alessandro Artusi, Kurt Debattista, and Alan Chalmers. 2012. Cultural heritage predictive rendering. Computer Graphics Forum 31 (2012), 1823-1836. Issue 6. https: //doi.org/10.1111/j.1467-8659.2012.02098.x 
Jassim Happa, Mark Mudge, Kurt Debattista, Alessandro Artusi, Alexandrino Gonçalves, and Alan Chalmers. 2010. Illuminating the past: State of the art. Virtual Reality 14, 3 (2010), 155-182. https://doi.org/10.1007/ s10055-010-0154-x

Lukas Hosek and Alexander Wilkie. 2012. An analytic model for full spectral sky-dome radiance. ACM Trans. Graph. 31 (2012), 95:1-95:9. https://doi.org/10.1145/2185520.2185591

IES TM-25 2013. Ray file format for the description of the emission property of light sources. Recommendation IES TM-25:2013. Illuminating Engineering Society.

ISO 15469:1997 1997. Spatial distribution of daylight - CIE standard overcast sky and clear sky. Standard ISO 15469:1997 (CIE 003/E-1996). ISO / CIE TC 3-15. Superseded by ISO 15469:2004 (CIE S 011/E:2003).

ISO 15469:2004 2004. Spatial distribution of daylight - CIE standard general sky. Standard ISO 15469:2004 (CIE S 011/E:2003). ISO / CIE TC 3-15. Reviewed and confirmed in 2018.

Henrik Wann Jensen. 2001. Realistic image synthesis using photon mapping. AK Peters / CRC Press, New York, US. https://doi.org/10.1201/9780429294907

James T. Kajiya. 1986. The rendering equation. In 13th Annual Conference on Computer Graphics and Interactive Techniques (SIGGRAPH). ACM, New York, NY, USA, 143-150. https://doi.org/10.1145/15886.15902

Joseph T. Kider, Rebecca L. Fletcher, Nancy Yu, Renata Holod, Alan Chalmers, and Norman I. Badler. 2009. Recreating early Islamic glass lamp lighting. In Proceedings of the 10th International Conference on Virtual Reality, Archaeology and Cultural Heritage (VAST'09). Eurographics Association, Aire-la-Ville, Switzerland, Switzerland, 33-40. https://doi.org/10.2312/VAST/VAST09/033-040

Jennifer. Komp. 2009. Römisches Fensterglas : Archäologische und archäometrische Untersuchungen zur Glasherstellung im Rheingebiet. Ph.D. Dissertation. Frankfurt am Main, Univ., Diss., 2007, Aachen.

Marek Krehel, Stephen Wittkopf, and Jérôme Kämpf. 2015. Characterisation and modelling of advanced daylight redirection systems with different goniophotometers. In Proceedings CISBAT 2015. EPFL, Lausanne, $211-216$. https://doi .org/10.5075/epfl-cisbat2015-211-216

Murat Kurt and Dave Edwards. 2009. A survey of BRDF models for computer graphics. SIGGRAPH Computer Graphics 43, 2 (May 2009), 4:1-4:7. https://doi.org/10.1145/1629216.1629222

Eleanor Lee, Taoning Wang, Jacob Jonsson, Greg Ward, Lars Oliver Grobe, Jan Wienold, and David GeislerMoroder. 2018. Generating high-resolution BSDFs for the direct beam component. International Radiance Workshop. https://www.radiance-online.org/community/workshops/2018-loughborough/presentations/ 03-HighResBSDFs.pdf

Wojciech Matusik, Hanspeter Pfister, Matt Brand, and Leonard McMillan. 2003. A data-driven reflectance model. ACM Transactions on Graphics 22, 3 (July 2003), 759-769. https://doi.org/10.1145/882262.882343

Inanici Mehlika. 2013. Dynamic daylighting simulations from static high dynamic range imagery using extrapolation and daylight coefficient methodologies. , 25-28 pages.

Stephanie Meyen, Florian Sutter, and Peter Heller. 2014. Near specular scatter analysis method with a new goniophotometer. In SPIE Optical Engineering + Applications, Vol. 9205, Reflection, Scattering, and Diffraction from Surfaces IV. International Society for Optics and Photonics, San Diego, California, US, 92050B-92050B-15. https://doi.org/10.1117/12.2061036

Addy Ngan, Frédo Durand, and Wojciech Matusik. 2005. Experimental analysis of BRDF models. In EGSR'05 16th Eurographics conference on Rendering Techniques. Eurographics Association, Konstanz, Germany, $117-226$.

Fred E Nicodemus, Joseph C Richmond, Jack J Hsia, Irving W Ginsberg, and Thomas Limperis. 1977. Geometrical considerations and nomenclature for reflectance. Vol. 160. US Department of Commerce, National Bureau of Standards, Washington, DC, USA.

Andreas Noback, Lars Oliver Grobe, and Franziska Lang. 2018. 21st Congress of the Association Internationale pour l'Histoire du Verre. https://doi.org/10.5281/zenodo.1414008

Margaret O'Hea. 2001. Glass from the 1992-93 excavations. In The Petra Church, Patricia Maynor Bikai (Ed.). American Center of Oriental Research, Amman, JO, 370-376.

Aenne Ohnesorg. 2011. Der naxische Lichtdom - Phänomen lichtdurchlässiger inselionischer Marmordächer. In Licht - Konzepte in der vormodernen Architektur. Schnell \& Steiner, Regensburg, 92-100. 
András Patay-Horváth. 2016. Der Zeustempel von Olympia. Rekonstruktionen des Tempels und des Ostgiebels im Vergleich. In 3D-Anwendungen in der Archäologie. Computeranwendungen und quantitative Methoden in der Archäologie (Berlin Studies of the Ancient World), Undine Lieberwirth and Irmela Herzog (Eds.), Vol. 34. Edition Topoi, Berlin, DE, 77-91. https://doi.org/10.17171/3-34-5

Richard Perez, Pierre Ineichen, Robert Seals, Joseph Michalsky, and Ronald Stewart. 1990. Modeling daylight availability and irradiance components from direct and global irradiance. Solar Energy 44 (1990), $271-289$. https://doi.org/10.1016/0038-092X(90)90055-H

Andrzej Piotrowski. 2006. Representational function of daylight in the Katholikon of Hosios Loukas. In 21st International Congress of Byzantine Studies. Ashgate Publishing Ltd, London, UK, 21-24.

A. J. Preetham, Peter Shirley, and Brian Smits. 1999. A practical analytic model for daylight. In Proceedings of the 26th Annual Conference on Computer Graphics and Interactive Techniques (SIGGRAPH '99). ACM Press/AddisonWesley Publishing Co., New York, NY, USA, 91-100. https://doi.org/10.1145/311535.311545

Ibrahim Reda and Afshin Andreas. 2008. Solar position algorithm for solar radiation applications. Technical Report. National Renewable Energy Laboratory.

Lucia Saguì. 2008. Glass in late antiquity. The continuity of technology and sources of supply. Brill, Leiden, NL, 212-231. https://doi.org/10.1163/ej.9789004165496.i-573.85

Roland Schregle. 2004. Daylight simulation with photon maps. Ph.D. Dissertation. Universität des Saarlandes, Saarbrücken, DE.

John C Stover. 2012. Optical scattering: Measurement and analysis. SPIE Optical Engineering Press, Bellingham, WA.

Niranjan Thanikachalam, Loic Baboulaz, Paolo Prandoni, and Martin Vetterli. 2016. VITRAIL: Acquisition, modeling, and rendering of stained glass. IEEE Transactions on Image Processing 25, 10 (Oct 2016), 4475-4488. https: //doi.org/10.1109/TIP.2016.2585041

Bruce Walter, Stephen R Marschner, Hongsong Li, and Kenneth E Torrance. 2007. Microfacet models for refraction through rough surfaces. In Proceedings of the 18th Eurographics Conference on Rendering Techniques (EGSR'07). Eurographics Association, Grenoble, France, 195-206. https://doi.org/10.2312/EGWR/EGSR07/195-206

Gregory Ward, Murat Kurt, and N. Bonneel. 2012. A practical framework for sharing and rendering real-world Bidirectional Scattering Distribution Functions. Report. LBNL.

Greg Ward, Murat Kurt, and Nicolas Bonneel. 2014. Reducing anisotropic BSDF measurement to common practice. In Proceedings of the Eurographics 2014 Workshop on Material Appearance Modeling: Issues and Acquisition (MAM '14). Eurographics Association, Lyon, F, 5-8.

Greg Ward and Rob Shakespeare. 1998. Rendering with Radiance. Morgan Kaufmann Publishers, San Francisco, CA.

Gregory Ward Larson, Holly Rushmeier, and Christine Piatko. 1997. A visibility matching tone reproduction operator for high dynamic range scenes. IEEE Transactions on Visualization and Computer Graphics 3, 4 (1997), 291-306. https://doi.org/10.1109/2945.646233

Frank Wiesenberg. 2016. Durchblick schaffen - zur römischen Flachglasherstellung. In Experimentelle Archäologie: Studien zur römischen Glastechnik, Bettina Birkenhagen and Frank Wiesenberg (Eds.). Schriften des Archäologieparks Römische Villa Borg, Vol. 1. Kulturstiftung für den Landkreis Merzig-Wadern, Marzig, DE, $49 f f$. 